\title{
Suppression of EAE and Prevention of Blood-Brain Barrier Breakdown after Vaccination with Novel Bifunctional Peptide Inhibitor
}

\author{
Ahmed H. Badawi ${ }^{\mathrm{a}}$, Paul Kiptoo ${ }^{\mathrm{a}}$, Wen-Tung Wang ${ }^{\mathrm{b}}$, In-Young Choi ${ }^{\mathrm{b}, \mathrm{c}, \mathrm{d}}$, Phil Lee ${ }^{\mathrm{b}, \mathrm{d}}$, \\ Charlotte M. Vines ${ }^{e}$, and Teruna J. Siahaan ${ }^{a, f}$ \\ aDepartment of Pharmaceutical Chemistry, University of Kansas, Lawrence, KS 66047 \\ bHoglund Brain Imaging Center, University of Kansas - Medical Center, Kansas City, KS 66160 \\ 'Department of Neurology, University of Kansas - Medical Center, Kansas City, KS 66160 \\ dDepartment of Molecular \& Integrative Physiology, University of Kansas - Medical Center, \\ Kansas City, KS 66160 \\ eDepartment of Microbiology, Molecular Genetics and Immunology, University of Kansas - \\ Medical Center, Kansas City, KS 66160
}

\begin{abstract}
The efficacy of bifunctional peptide inhibitor (BPI) in preventing blood-brain barrier (BBB) breakdown during onset of experimental autoimmune encephalomyelitis (EAE) and suppression of the disease was evaluated in mice. The mechanism that defines how BPI prevents the disease was investigated by measuring the in vitro cytokine production of splenocytes. Peptides were injected 5 to 11 days prior to induction of EAE, and the severity of the disease was monitored by a standard clinical scoring protocol and change in body weight. The BBB breakdown in diseased and treated mice was compared to that in normal control mice by determining deposition of gadolinium diethylenetriaminepentaacetate (Gd-DTPA) in the brain using magnetic resonance imaging (MRI). Mice treated with PLP-BPI showed no or low indication of EAE as well as normal increase in body weight. In contrast, mice treated with the control peptide or PBS showed a decrease in body weight and a high disease score. The diseased mice had high deposition of GdDTPA in the brain, indicating breakdown in the BBB. However, the deposition of Gd-DTPA in PLP-BPI-treated mice was similar to that in normal control mice. Thus, PLP-BPI can suppress EAE when administered as a peptide vaccine and maintain the integrity of the BBB.
\end{abstract}

\section{Keywords}

Blood Brain Barrier; Experimental Autoimmune Encephalomyelitis; Bifunctional Peptide Inhibitor; Antigen Presenting Cell; T cell; Magnetic Resonance Imaging

\footnotetext{
(C) 2011 Elsevier Ltd. All rights reserved.

fAddress correspondence to: Teruna J. Siahaan, Department of Pharmaceutical Chemistry, The University of Kansas, 2095 Constant Avenue, Lawrence, Kansas 66047, Phone: 785-864-7327, Fax: 785-864-5736, siahaan@ku.edu.

Publisher's Disclaimer: This is a PDF file of an unedited manuscript that has been accepted for publication. As a service to our customers we are providing this early version of the manuscript. The manuscript will undergo copyediting, typesetting, and review of the resulting proof before it is published in its final citable form. Please note that during the production process errors may be discovered which could affect the content, and all legal disclaimers that apply to the journal pertain.
} 


\section{INTRODUCTION}

Multiple sclerosis (MS) is a neurological disease in which the body's immune system recognizes protein fragments of the myelin sheath as antigenic and initiates an inflammatory response in the central nervous system (CNS). This immune response leads to breakdown of the BBB integrity and demyelination of neurons (Lassmann, 2001). Major proteins that make up the myelin sheath are myelin basic protein (MBP), myelin oligodendrocyte glycoprotein (MOG) and proteolipid protein (PLP), which can be recognized as antigens by $\mathrm{CD}^{+} \mathrm{T}$ cells, and most likely promote neurodegenerative diseases such as MS. Activation of T cells takes place after the delivery of two signals by antigen-presenting cells (APC) (Grakoui et al., 1999; Tseng and Dustin, 2002). The first signal (Signal I) is the interaction between the T-cell receptor (TCR) and the antigen-loaded major histocompatibility complex class-II (MHC-II). The second signal (Signal II) is provided by costimulatory molecules (CD28/B-7) (Jenkins and Johnson, 1993; June et al., 1994), and is strengthened by the interaction between adhesion molecules such as intercellular adhesion molecule-1 (ICAM-1) and leukocyte function-associated antigen-1 (LFA-1) (Valitutti et al., 1995). Novel bifunctional peptide inhibitor (BPI) molecules are composed of an antigenic peptide fragment covalently conjugated to an adhesion molecule fragment (Manikwar et al., 2011).

BPI molecules were designed based on a proposed mechanism that they can bind simultaneously to the MHC-II and adhesion molecules on the surface of APC such as dendritic cells (DC). This simultaneous binding is proposed to prevent proper delivery of signals through the immunological synapse and, therefore, hinder the induction of a specific immune response. Consequently, only a subpopulation of $\mathrm{T}$ cells that recognize the antigenic peptide fragment in the BPI would be affected and, thus, tolerance toward that particular antigen would be restored.

In order to study the etiology of MS as well as to develop new therapies for the disease, the EAE animal model can be used. EAE animals undergo a pathogenesis very similar to MS, including inflammation of the CNS and breakdown of the BBB. EAE is an inflammatory disease characterized by the differentiation and proliferation of type-17 helper $\mathrm{T}$ cells $\left(T_{H} 17\right)$ (Zepp et al., 2011) and type-1 helper $T$ cells $\left(T_{H} 1\right)$ (Hedegaard et al., 2008). To suppress or prevent disease, several therapies have been designed to down-regulate these pro-inflammatory $\mathrm{T}$ cells and promote the activation of the regulatory and suppressor immune response by promoting the differentiation and proliferation of regulatory $\mathrm{T}$ cells $\left(\mathrm{T}_{\text {reg }}\right)$ (Wraith, 2009) and type-2 helper $\mathrm{T}$ cells $\left(\mathrm{T}_{\mathrm{H}} 2\right.$ ) (Liblau et al., 1995). Many potential therapies for MS (i.e., peptides and small molecules) are being evaluated in EAE animal models after induction of disease with antigen(s). Our previous studies have shown that BPI molecules suppressed EAE in mice upon BPI treatment during disease induction or after the initial progress of the disease (Kobayashi et al., 2007; Manikwar et al., 2011). In the current study, we evaluated the in vivo efficacy after vaccination of the mice with peptides, i.e., before induction of disease. We hypothesized that the vaccination with Ac-PLP-BPI-NH $\mathrm{N}_{2}$ (PLP-BPI) would stimulate a regulatory or tolerogenic response in mice; therefore, when EAE was induced with antigen in the presence of adjuvant, the disease would not develop due to priming of the regulatory response of the immune system by PLP-BPI.

The severe CNS inflammation in MS and EAE leads to BBB breakdown and CNS lymphocyte infiltration (Floris et al., 2004). It is not yet clear whether the breakdown of the BBB is a secondary effect of the disease or an initiator of the disease. A therapy such as Tysabri ${ }^{\circledR}$ has been shown to prevent lymphocyte infiltration into the brain (Bielekova and Becker, 2010). Studies suggest a link between the initiation of inflammation and activation of leukocytes leading to the breakdown of the BBB (Minagar and Alexander, 2003; Sun et al., 2000). Therefore, we propose that blocking the induction of the pro-inflammatory $\mathrm{T}$ cells can prevent the disruption of the BBB after induction of EAE. 
PLP-BPI is a well-characterized BPI molecule in suppressing the EAE mouse model when administered after disease stimulation. PLP-BPI is composed of the antigenic peptide PLP $_{139-151}$ (PLP) (Tuohy et al., 1989) covalently conjugated to the ICAM-1 ligand, LABL peptide (derived from LFA-1) (Tibbetts et al., 1999, 2000; Yusuf-Makagiansar et al., 2001, 2007) via a stable linker composed of glycine and aminocaproic acid (Figure 1). In this study, we tested the novel use of PLP-BPI as a peptide vaccine, the in vivo efficacy of PLPBPI was evaluated and the effect of PLP-BPI treatment on preventing breakdown of the BBB was determined by the levels of BBB permeation of Gd-DTPA using MRI in normal (no EAE) mice, PBS-treated EAE mice and PLP-BPI-treated mice. The brain deposition of Gd-DTPA was determined using contrast enhanced T1-weighted MRI. Scans were performed on various brain regions and enhancement of signal before and after Gd-DTPA injection was imaged and quantified. Finally, the immune-modulation mechanisms were elucidated by determining the cytokine production of splenocytes that were isolated from PBS- and PLP-BPI-treated mice.

\section{MATERIALS AND METHODS}

\subsection{Mice}

All protocols for experiments involving SJL/J $\left(\mathrm{H}-2^{\mathrm{s}}\right)$ (Charles River, Wilmington, MA) were approved by the University's Institutional Animal Care and Use Committee. The mice were housed under specific pathogen-free conditions at a facility at the University of Kansas, which is approved by the Association for Assessment and Accreditation of Laboratory Animal Care.

\subsection{Peptide synthesis}

PLP $_{139-151}$ (HSLGKWLGHPDKF) and PLP-BPI (Ac-HSLGKWLGHPDKF(AcpGAcpGAcp) $)_{2}$-ITDGEATDSG- $\mathrm{NH}_{2}$, Ac being an acetyl group and Acp being $\varepsilon$ aminocaproic acid) were synthesized with 9-fluorenylmethyloxy-carbonyl-protected amino acid chemistry on an appropriate PEG-PS ${ }^{\mathrm{TM}}$ resin (Applied Biosystems, Foster City, CA) using the automated peptide synthesis system (Pioneer ${ }^{\mathrm{TM}}$ :PerSeptive Biosystems, Framingham, MA). Cleavage of the peptides from the resin and removal of the protecting groups from the side-chain were carried out using 90\% TFA with 10\% scavenger reagents (1,2-ethane dithiol (3\%), anisole (2\%), and thioanisole (5\%)). The crude peptides were purified by reversed-phase HPLC using a semi-preparative $\mathrm{C} 18$ column with a gradient of solvent A (95\%/5\% $=\mathrm{H}_{2} \mathrm{O}(0.1 \%$ TFA)/acetonitrile) and solvent B (100\% acetonitrile). The purity of the peptides was analyzed by HPLC using an analytical C18 column. The identity of the synthesized peptide was confirmed by electrospray ionization mass spectrometry.

\subsection{Induction and treatment of EAE}

SJL/J female mice (5-7 weeks-old) were immunized subcutaneously (s.c.) with $200 \mu \mathrm{g}$ PLP in a $0.2 \mathrm{ml}$ emulsion comprised of equal volumes of PBS and complete Freund's adjuvant (CFA) containing killed mycobacterium tuberculosis strain H37RA (at a final concentration of $4 \mathrm{mg} / \mathrm{ml}$, Difco, Detroit, MI). The PLP/CFA emulsion was administered to regions above the shoulder and the flanks (total 4 sites; $50 \mu 1$ at each injection site). In addition, $200 \mathrm{ng}$ of pertussis toxin (List Biological Laboratories, Campbell, CA) was injected intraperitoneally (i.p.) on the day of immunization (day 0 ) and $48 \mathrm{~h}$ post-immunization. The clinical scores that reflect the disease progression were determined by the same observer in a blinded fashion using a scale ranging from 0 to 5 as follows: 0 - no clinical symptoms, 1 - limp tail or waddling gait with tail tonicity; 2 - waddling gait with limp tail (ataxia); 2.5 - ataxia with partial paralysis of one limb; 3 - full paralysis of one limb; 3.5 - full paralysis of one limb with partial paralysis of the second limb; 4 - full paralysis of two limbs; 4.5 - full paralysis 
of two limbs with partial paralysis of forelimbs; 5 - moribund or dead. Body weight was also measured daily.

For the vaccination study, the mice received three s.c. injections of either $100 \mu \mathrm{L}$ vehicle (PBS) or $100 \mu \mathrm{L}$ of treatment peptides (100 nmol/injection/day) 11,8 , and 5 days prior to induction of disease on day 0. PLP-BPI's potency was compared to a negative control (PBS) and a positive control (PLP).

\subsection{In vitro cytokine production assay}

In vitro cytokine assays were performed following a protocol similar to that reported previously (Youssef et al., 2002). SJL/J mice were treated with PBS (100 $\mu 1)$ and PLP-BPI (100 nmol/100 $\mu 1 /$ injection) on days $-11,-8$, and -5 followed by injection of PLP/CFA and pertussis toxin as described in section 2.3 to induce EAE. Spleens were isolated from three PLP-BPI- and PBS-treated mice on the day of maximum disease (i.e., day 15). Single cell suspensions of splenocytes were harvested by gently mashing the spleen through a cell strainer using the rubber end of a 1-ml syringe in a petri dish containing serum-free RPMI-1640 supplemented with 10\% fetal bovine serum, $100 \mathrm{U}$ penicillin/100 $\mu \mathrm{g}$ streptomycin, $2 \mathrm{mM}$ L-glutamine and $50 \mu \mathrm{M}$ 2-mercaptoethanol. Red blood cells were then lysed using ACK lysis buffer (Invitrogen). The remaining splenocytes were then washed three times with serum-free RPMI-160 media (Cellgro). The cells were then primed with PLP $(20 \mu \mathrm{M})$ in a 24 -well plate $\left(5 \times 10^{6}\right.$ cells/well). Supernatants of cell cultures were collected for cytokine detection 72 hours later and stored in a $-80^{\circ} \mathrm{C}$ freezer until analysis. Secreted IL-2, IL-4, IL-5, IL-6, IL-17, and IFN- $\gamma$ were measured by quantitative ELISAbased Q-Plex ${ }^{\mathrm{TM}}$ assay (Quansys Biosciences, Logan, UT).

\subsection{MRI scans}

To evaluate the effect of PLP-BPI treatment on the breakdown of the BBB, three different groups of animals were used. The first group consisted of five normal SJL/J mice with no EAE induction. The second and third groups of mice were treated with PBS and PLP-BPI, respectively, on days $-11,-8$, and -5 , followed by induction of EAE with PLP/CFA on day 0 as described in section 2.3.

In vivo MRI scans were performed using contrast enhanced T1-weighted imaging to determine the extent of BBB breakdown at the highest peak of the disease at 15 days after induction of EAE. The contrast agent, Gd-DTPA (Magnevist, Bayer HealthCare, Leverkusen, Germany), was delivered via an i.p. catheter, which enabled us to acquire images before and after Gd-DTPA infusion under an identical experimental setup. For MRI experiments, the animals were anesthetized using $3 \%$ isoflurane initially followed by $1-2 \%$ isoflurane in a gas mixture of air and oxygen (ratio $=1: 1)$. Before MRI scans were performed, an i.p. catheter (Insyte Autogard, 22 GA, $0.9 \times 25 \mathrm{~mm}$, Becton Dickinson, Sparks, MD) was inserted in to the animal's peritoneal cavity and secured with tapes.

All MR imaging was performed with a $9.4 \mathrm{~T}$ horizontal bore spectrometer equipped with a Varian INOVA console (Varian Inc., Palo Alto, CA) and gradient coils ( $40 \mathrm{G} / \mathrm{cm}, 250 \mu \mathrm{s})$ of $12 \mathrm{~cm}$ in diameter (Magnex Scientific, Abingdon, UK). The animal was positioned supine in an acrylic sled with its head held steady by using a nose cone for anesthesia delivery. The animal's body temperature was monitored by a rectal temperature sensor (Cole-Palmer, Vernon Hills, IL) and maintained at $37 \pm 0.5^{\circ} \mathrm{C}$ using a blanket with warm water circulation. The animal's respiratory rate was monitored using a respiration pillow (SA instruments, Stony Brook, NY). A quadrature RF surface coil was placed on top of the animal's head to acquire T1-weighted spin-echo MR images before and after a bolus infusion of Gd-DTPA $(0.6 \mathrm{mmol} / \mathrm{kg}$ body weight $)$. The imaging parameters were TE/TR $=12.5 / 600 \mathrm{~ms}$, matrix 
size $=256 \times 256$, field of view $=20 \times 20 \mathrm{~mm}$, slice thickness $=0.5 \mathrm{~mm}$, and number of averages $=2$. The corresponding nominal image resolution was $78 \times 78 \times 500 \mu \mathrm{m}^{3}$. The timing of the post-contrast administration MRI scan was set to 20 min to allow uptake of Gd-DTPA into the blood from the i.p. injection and deposition in the brain.

MR data analysis was performed by calculating the percent signal enhancement due to GdDTPA deposition in the brain using the following equation: $\left(\left[\mathrm{v}_{1}-\mathrm{v}_{0}\right] / \mathrm{v}_{0}\right)$, where $\mathrm{v}_{1}$ is the MR signal after Gd-DTPA injection, and $\mathrm{v}_{0}$ is the MR signal before Gd-DTPA injection. The percent signal enhancement was measured in six regions of interest (ROI) of the brain, including spinal cord, brain stem, cerebellum, hippocampus, cortex, and striatum.

\subsection{Statistical analysis}

Statistical analysis was done using one-way analysis of variance followed by Fisher's least significance difference to compare the different parameters, including EAE clinical scores, change in body weights, in vitro cytokine production, and percent MR signal enhancement. All statistical analyses were performed using StatView software (SAS Institute, Inc., Cary, $\mathrm{NC)}$. A $p$-value of less than 0.05 was used as the criterion for statistical significance.

\section{RESULTS}

\subsection{Suppression of EAE by PLP-BPI}

It has been shown previously that PLP-BPI molecules have better efficacy in suppressing EAE than PLP peptide when injected intravenous (i.v.) on days 4, 7, 10 and 14 (Kobayashi et al., 2007, 2008;) or injected s.c. on days 4, 7, and 10 (Zhao et al., 2010) after disease stimulation using a PLP/CFA emulsion on day 0. Here, the efficacy of PLP-BPI as a peptide vaccine was evaluated following s.c. injections of PLP-BPI on days $-11,-8$, and -5 prior to stimulation on day 0 with PLP/CFA emulsion.

Disease severity was measured using a standard disease scoring protocol (Figure 2A), which ranges from 0 to 5. The first sign of EAE was evident in the PBS- and PLP-treated mice on days 11-12. The peak of the disease was between days 14 and 17 with a maximum average disease score of $2.30 \pm 0.43$ for PBS-treated and $1.50 \pm 0.31$ for PLP-treated mice $(n=12)$. After the peak of the disease, the mice slowly went into remission. Most of the PLP-BPItreated mice were disease-free with only one mouse having slight weakness in its tail, this resulted in a maximum average disease score of $0.08 \pm 0.08(n=12)$. Therefore, PLP-BPI was able to significantly suppress EAE compared to PBS $(p<0.0001)$ and PLP $(p<$ 0.0001). The efficacy of PLP-BPI was also evaluated using percent change in body weight of the mice. The PBS-treated mice showed a significant loss of body weight (approximately $15 \%)$ when compared to the PLP-BPI-treated mice $(p<0.0001)$. The PLP-treated group showed about $10 \%$ loss of body weight which was also significantly lower than the PLPBPI-treated mice $(p<0.001)$. The PLP-BPI-treated group showed no loss in body weight (Figure 2B). A summary of the results is shown in Table 1.

\subsection{In vitro cytokine production}

To examine the cytokines induced by PLP-BPI and better understand the immune response, splenocytes from PLP-BPI-treated and PBS-treated mice were isolated on day 15. The type of immune cell differentiation upon treatment can be determined by evaluating the type of cytokines secreted from the splenocyte culture. Although this method will not provide an exact concentration of cytokines in systemic circulation, it will provide relative levels of cytokines produced by cells in the mice following different treatments. If there is a general inflammatory response, one would expect to see a greater production of pro-inflammatory cytokines (IL-6, IL-17 and IFN- $\gamma$ ). If there were an activation of the regulatory and 
suppressor immune response, there would be a greater concentration of regulatory (IL-2) (Malek, 2003) and suppressor cytokines (IL-4 and IL-5).

EAE is believed to be predominantly a $\mathrm{T}_{\mathrm{H}} 17$ - and $\mathrm{T}_{\mathrm{H}} 1$-mediated disease; therefore, the in vitro production of cytokine markers for both types of inflammatory $\mathrm{T}$ cells was evaluated (Figure 3). In these studies, resident APC served to activate the T cells that had been isolated from mice at the height of the disease in a recall assay, using PLP as the target antigen. Following a 72-hour incubation with PLP, splenocytes isolated from PBS-treated mice produced approximately three times higher IL-17 than PLP-BPI-treated mice, indicating a greater presence of $\mathrm{T}_{\mathrm{H}} 17$ cells in PBS-treated than in PLP-BPI-treated mice $(p<0.0001)$. There was a significant increase in the production of IFN- $\gamma$ as well $(p<0.05)$, but only a slight increase in the production of IL-6 that was not significantly different $(p>0.05)$ in the culture supernatants isolated from the PBS-treated mice than that of PLP-BPI-treated mice. From these results, we concluded that PLP-BPI down-regulated the $\mathrm{T}_{\mathrm{H}} 1$ phenotype.

The next step was to evaluate the role of PLP-BPI in skewing the response toward regulatory $\left(\mathrm{T}_{\text {reg }}\right)$ and suppressor $\left(\mathrm{T}_{\mathrm{H}} 2\right) \mathrm{T}$ cell phenotypes (Figure 4). In the recall assay, splenocytes from PLP-BPI-treated mice produced significantly higher IL-2 $(p<0.0001)$ than those from PBS treated mice, indicating that PLP-BPI may promote $\mathrm{T}_{\text {reg }}$ differentiation (D'Cruz and Klein, 2005; Fontenot et al., 2005). More remarkably, splenocytes from PLPBPI-treated mice produced significantly higher levels of IL-4 $(p<0.0001)$ and IL-5 ( $p<$ 0.001) when compared to PBS-treated mice. Our observation suggests that PLP-BPI promoted a shift toward $\mathrm{T}_{\mathrm{H}} 2$ differentiation and proliferation.

\subsection{MRI data}

Cytokine data demonstrated that injection of PLP-BPI subcutaneously on days 11, 8, and 5 prior to induction of disease promoted the regulatory response and lowered the inflammatory response. It is believed that CNS inflammation leads to breakdown of the BBB. We proposed that PLP-BPI increased the regulatory immune response and suppressed the activation of inflammatory immune response, which would prevent the breakdown of the BBB. We used MRI following injection of Gd-DTPA to monitor the breakdown of the BBB. The PBS-treated mice developed EAE and showed high enhancement of Gd-DTPA signal in most brain regions compared to normal mice (negative control); this result indicated that the BBB of PBS-treated mice was compromised. In contrast, there was no obvious enhancement in Gd-DTPA signal in the brain of PLP-BPI-treated mice compared to normal mice without disease induction (Figure 5). These result indicated that there was no BBB breakdown in PLP-BPI-treated mice. The quantitative enhancement of Gd-DTPA signals in different regions of the brain from all three groups of mice is shown in Figure 6. There was a consistent trend of signal enhancement in all regions of the brains of PBS-treated mice. However, different regions of the brain of PLP-BPI-treated mice had signals similar to those of normal mice. Taken together, from these results we concluded that PLP-BPI can prevent the breakdown of the BBB by suppressing the inflammatory immune response, which is likely due to the generation of regulatory and suppressor cells following vaccination.

\section{DISCUSSION}

Antigenic peptides have recently found an application for the treatment of allergic and autoimmune diseases in a procedure known as soluble antigen-specific immunotherapy (SIT). Wraith and colleagues proposed a potential mechanism of action for the way that soluble antigenic peptides modulate the immune response (Larche and Wraith, 2005). Empty MHC-II molecules on the surface of APC such as DC are capable of being loaded by exogenous peptides (Santambrogio et al., 1999). Therefore, it is proposed by Wraith and colleagues that soluble antigenic peptides can bind directly to the empty MHC-II molecules 
on the surface of immature DC (iDC) with out being internalized and processed and lead to the induction of a regulatory response by promoting a $\mathrm{T}_{\text {reg }}$ phenotype. In this case, the induction of the regulatory $\mathrm{T}$-cell response leads to restored tolerance for specific antigens in the treatment of autoimmune diseases such as multiple sclerosis (Bai et al., 1997; Metzler and Wraith, 1996), rheumatoid arthritis (RA) (Meyer, 2000), and type-1 diabetes (T1D) (Murray et al., 2007).

Bifunctional peptide inhibitors (BPI) have been shown to suppress EAE (Manikwar et al., 2011), T1D (Murray et al., 2007), and RA (unpublished data) and are consistently more efficient at suppressing disease than the corresponding parent antigenic peptides. We hypothesize that the antigenic peptide and the adhesion peptide of the BPI molecule bind to MHC-II and ICAM-1 molecules, respectively, on the surface of APC. This simultaneous binding will interfere with the maintenance of the functional immunological synapse at the APC-T cell interface, a step necessary for full activation of an immunogenic response (Lee et al., 2002; van der Merwe, 2002). Alternatively, the two molecules on the surface of the APC are clustered and internalized. Without the appropriate delivery of signals, the cells fail to induce an inflammatory response and instead promote the differentiation of naïve $\mathrm{T}$ cells toward regulatory and/or suppressor T-cell phenotypes. A third possible mechanism is that the antigenic peptide fragment of the BPI molecule could bind directly to the empty MHC-II molecules on the surface of iDC and act similarly to the antigenic peptide on its own. If this is the case, binding of a naïve T cell to an APC would induce the differentiation to regulatory $\mathrm{T}$ cells as with the administration of soluble antigenic peptide alone. However, the mechanism of action of BPI molecules remains to be fully elucidated.

Previously, PLP-BPI has been administered in solution i.v. (Kobayashi et al., 2007) and s.c. as well as in a controlled-release fashion using nanoparticles (Zhao et al., 2010). It was shown that s.c. administration was more effective than i.v. administration of PLP-BPI. In addition, increasing the length of the linker as well as capping the $\mathrm{N}$ - and $\mathrm{C}$ - termini proved to enhance the in vivo efficacy of the peptide (Kobayashi et al., 2008). In these studies, PLPBPI prevented the onset of disease significantly when the peptide was administered after the induction of disease. In addition, mice treated with PLP-BPI after the onset of disease went into remission faster than those treated with PBS.

In our proposed mechanism of action of PLP-BPI, in which the peptide induces the regulatory response, injection of PLP-BPI prior to induction of disease should protect the mouse from developing severe EAE. Therefore, our study was designed to investigate the effects of PLP-BPI and PLP on the disease progression when these peptides were administered prior to disease induction. It is interesting that three subcutaneous injections of PLP-BPI at 11, 8, and 5 days prior to induction of disease effectively suppressed the development of EAE compared to PLP peptide and PBS. The superior efficacy of PLP-BPI relative to PLP is consistent with what we found previously when injecting the peptides after induction of disease (Kobayashi et al., 2007, 2008; Zhao et al., 2010). Unlike in previous studies (Kobayashi et al., 2008) in which $43.8-45.5 \%$ of the mice developed anaphylaxis, only $8.33 \%$ (1 out of 12) developed anaphylaxis when PLP-BPI is injected as a peptide vaccine, thus adding another advantage to vaccination. Administration of PLP-BPI several days prior to induction of disease proves to us that mechanistically it works by modulating the immune system and not simply acting as a protein/peptide blocker since we know that in vivo half-life of PLP-BPI is approximately 2 hours (Ridwan et al., 2010). Although five days elapsed between the last injection of peptide and disease induction, the effect of PLP-BPI persists after the peptide is eliminated from the systemic circulation. It is still not completely clear why PLP-BPI has better efficacy than PLP, but it is possibly due to the presence of LABL peptide on PLP-BPI, which could improve peptide binding to DC in addition to hindering the development of the immunological synapse. Further investigations need to be 
carried out for elucidating the difference in the mechanisms of action between PLP-BPI and PLP.

EAE is a demyelinating disease that mimics the inflammatory disease MS, which is driven by the induction of pro-inflammatory $\mathrm{T}$ cells such as $\mathrm{T}_{\mathrm{H}} 17$ and $\mathrm{T}_{\mathrm{H}} 1$. Restoring tolerance to specific myelin sheath antigens has become the most important strategy for the treatment of EAE and MS. Establishing the immuno-tolerant state has become possible due to the production of cytokines that probably promote the development of regulatory $\left(\mathrm{T}_{\text {reg }}\right)$ and suppressor T cells $\left(\mathrm{T}_{\mathrm{H}} 2\right)$ cells. Our cytokine studies indicated that splenocytes from PLPBPI-treated mice produced a lower level of IL-17, which would lead to a decreased population of $\mathrm{T}_{\mathrm{H}} 17$ cells when compared to PBS-treated mice. There is some controversy on the importance of IL-17 in the pathogenesis of EAE (Haak et al., 2009a) since it's been reported that the absence of IL-17 has not affected the progression of the disease (Haak et al. 2009b). However, $\mathrm{T}_{\mathrm{H}} 17$ cells have been shown to have a vital role in the development of EAE (Cao et al., 2011; Zepp et al., 2011) and the IL-17 function is not yet completely clear but it is a key marker for $\mathrm{T}_{\mathrm{H}} 17$ cells. In the current study, we also reported that PLP-BPItreated mice had reduced levels of the $\mathrm{T}_{\mathrm{H}} 1$ cytokines as well, as indicated by the decrease in secretion of IL- 6 and IFN- $\gamma$. The next step was to evaluate whether PLP-BPI induced expression of cytokines that promote $\mathrm{T}_{\text {reg }}$ and $\mathrm{T}_{\mathrm{H}} 2$ cells, both of which have been associated with the amelioration of EAE. IL-2 levels were significantly greater in PLP-BPI-treated mice than in PBS-treated mice; this strongly suggests that there was skewing of the immune response toward the production of $\mathrm{T}_{\text {reg }}$ cells. In addition, PLP-BPI led to a prominent shift toward a $\mathrm{T}_{\mathrm{H}} 2$ profile as reflected by the increased production of IL- 4 and IL- 5 .

Inflammation and leukocyte recruitment to the CNS during MS and EAE are known to cause BBB breakdown (Abbott et al., 2006; Huber et al., 2001). The cellular infiltration is initiated by the interaction of LFA- 1 on leukocytes and ICAM- 1 on the surface of vascular endothelial cells of the brain (i.e., BBB) (Prendergast and Anderton, 2009). It has been shown that $\mathrm{T}_{\mathrm{H}} 1$ (O'Connor et al., 2008) and $\mathrm{T}_{\mathrm{H}} 17$ (Reboldi et al., 2009) cells may enter the CNS during EAE. The production of inflammatory cytokines is believed to lead to BBB impairment (Abbott et al., 2006). Administration of PLP-BPI led to a reduction in the levels of inflammatory cytokines and, therefore, it is proposed that administration of PLP-BPI prevents the destruction of the BBB in EAE-induced mice due to its ability to modulate the immune response. This idea is supported by our observations from the MRI studies in determining the extent of the breakdown of the BBB of PLP-BPI- and PBS-treated mice compared to normal mice. The breakdown of the BBB can be assessed by determining the amount of Gd-DTPA that was deposited in the brain upon its permeation through the BBB. This is very important because the breakdown of the BBB is believed to precede cellular infiltration, which leads to destruction of the myelin sheath. It is remarkable that PLP-BPItreated mice had similar amounts of Gd-DTPA brain distributed to all brain regions compared to normal healthy mice. In contrast, there was greater Gd-DTPA deposition in different brain regions of PBS-treated mice compared to PLP-BPI-treated and healthy mice. We observed a significant enhancement of signal in the cerebellum of EAE mice treated with PBS compared to that in PLP-BPI-treated mice $(p<0.05)$. We also observed a difference $(p=0.06)$ in the enhancement of signal in the spinal cord between diseased mice and PLP-BPI-treated mice. It has been demonstrated that the cerebellum and the spinal cord are equally susceptible regions for BBB breakdown in this EAE model (Tonra et al., 2001). It is evident that the integrity of the BBB of PLP-BPI-mice is maintained to the same degree as in healthy mice, and PBS-treated mice have a breach of the BBB. Thus, PLP-BPI functions prior to the breakdown of the BBB, possibly by suppressing the activation of immune cells prior to their infiltration into the brain. Additionally, PLP-BPI could prevent the infiltration of immune cells by blocking ICAM-1/LFA-1-mediated immune cell adhesion to the vascular endothelial cells of the BBB. 
In conclusion, PLP-BPI, when administered as a peptide vaccine, suppresses EAE. Administration of PLP-BPI prior to induction of disease led to expression of regulatory and suppressor immune cytokines that mediate suppression of the inflammatory immune responses as shown by the in vitro cytokine production study. The inhibition of the inflammatory response by PLP-BPI prevented the breakdown of the BBB in EAE-induced mice. Further studies are necessary to elucidate the mechanisms of action of PLP-BPI in comparison to those of PLP peptide alone. In the future, we plan to study the effect of a long-term effect of PLP-BPI as a vaccine.

The following are the highlights of the manuscript:

1. Vaccination with PLP-BPI inhibited the onset and progression of EAE.

2. PLP-BPI promotes a shift towards $T_{\text {reg }}$ and $T_{H} 2$ rather than a $T_{H} 17$ or $T_{H} 1$.

3. Vaccination with PLP-BPI prevented the breakdown of the BBB.

\section{Abbreviations used}

EAE experimental autoimmune encephalomyelitis

BPI bifunctional peptide inhibitor

Gd-DTPA gadolinium diethylenetriaminepentaacetate

\section{Acknowledgments}

We would like to thank the National Institutes of Health (R01-AI-063002, R56-AI-063002 and R01-RR-06443), Vaccinogenesis Training Grant (NIH-066335), National Multiple Sclerosis Society, and the Institute for Advancing Medical Innovation (The University of Kansas - Cancer Center) for supporting this work. In addition, the Hoglund Brain Imaging Center is partly supported by NIH (C76 HF00201 and P30 HD002528) and the Hoglund Family Foundation. We are also grateful to Nancy Harmony for her help in proofreading this manuscript.

\section{REFERENCES}

Abbott NJ, Ronnback L, Hansson E. Astrocyte-endothelial interactions at the blood-brain barrier. Nat Rev Neurosci. 2006; 7:41-53. [PubMed: 16371949]

Bai XF, Shi FD, Xiao BG, Li HL, van der Meide PH, Link H. Nasal administration of myelin basic protein prevents relapsing experimental autoimmune encephalomyelitis in DA rats by activating regulatory cells expressing IL-4 and TGF-beta mRNA. J Neuroimmunol. 1997; 80:65-75. [PubMed: 9413260]

Bielekova B, Becker BL. Monoclonal antibodies in MS: mechanisms of action. Neurology. 2010; 74 Suppl 1:S31-S40. [PubMed: 20038761]

Cao W, Yang Y, Wang Z, Liu A, Fang L, Wu F, Hong J, Shi Y, Leung S, Dong C, Zhang JZ. Leukemia inhibitory factor inhibits $T$ helper 17 cell differentiation and confers treatment effects of neural progenitor cell therapy in autoimmune disease. Immunity. 2011; 35:273-284. [PubMed: 21835648]

D'Cruz LM, Klein L. Development and function of agonist-induced CD25+Foxp3+ regulatory T cells in the absence of interleukin 2 signaling. Nat Immunol. 2005; 6:1152-1159. [PubMed: 16227983]

Floris S, Blezer EL, Schreibelt G, Dopp E, van der Pol SM, Schadee-Eestermans IL, Nicolay K, Dijkstra CD, de Vries HE. Blood-brain barrier permeability and monocyte infiltration in experimental allergic encephalomyelitis: a quantitative MRI study. Brain. 2004; 127:616-627. [PubMed: 14691063]

Fontenot JD, Rasmussen JP, Gavin MA, Rudensky AY. A function for interleukin 2 in Foxp3expressing regulatory T cells. Nat Immunol. 2005; 6:1142-1151. [PubMed: 16227984] 
Grakoui A, Bromley SK, Sumen C, Davis MM, Shaw AS, Allen PM, Dustin ML. The immunological synapse: a molecular machine controlling T cell activation. Science. 1999; 285:221-227. [PubMed: 10398592]

Haak S, Gyulveszi G, Becher B. Th17 cells in autoimmune disease: changing the verdict. Immunotherapy. 2009a; 1:199-203. [PubMed: 20635941]

Haak S, Croxford AL, Kreymborg K, Heppner FL, Pouly S, Becher B, Waisman A. IL-17A and IL-17F do not contribute vitally to autoimmune neuro-inflammation in mice. J Clin Invest. 2009b; 119:61-69. [PubMed: 19075395]

Hedegaard CJ, Krakauer M, Bendtzen K, Lund H, Sellebjerg F, Nielsen CH. T helper cell type 1 (Th1), Th2 and Th17 responses to myelin basic protein and disease activity in multiple sclerosis. Immunology. 2008; 125:161-169. [PubMed: 18397264]

Huber JD, Witt KA, Hom S, Egleton RD, Mark KS, Davis TP. Inflammatory pain alters blood-brain barrier permeability and tight junctional protein expression. Am J Physiol Heart Circ Physiol. 2001; 280:H1241-H1248. [PubMed: 11179069]

Jenkins MK, Johnson JG. Molecules involved in T-cell costimulation. Curr Opin Immunol. 1993; 5:361-367. [PubMed: 7688514]

June CH, Bluestone JA, Nadler LM, Thompson CB. The B7 and CD28 receptor families. Immunol Today. 1994; 15:321-331. [PubMed: 7522010]

Kobayashi N, Kiptoo P, Kobayashi H, Ridwan R, Brocke S, Siahaan TJ. Prophylactic and therapeutic suppression of experimental autoimmune encephalomyelitis by a novel bifunctional peptide inhibitor. Clin Immunol. 2008; 129:69-79. [PubMed: 18676182]

Kobayashi N, Kobayashi H, Gu L, Malefyt T, Siahaan TJ. Antigen-specific suppression of experimental autoimmune encephalomyelitis by a novel bifunctional peptide inhibitor. J Pharmacol Exp Ther. 2007; 322:879-886. [PubMed: 17522343]

Larche M, Wraith DC. Peptide-based therapeutic vaccines for allergic and autoimmune diseases. Nat Med. 2005; 11:S69-S76. [PubMed: 15812493]

Lassmann H. Classification of demyelinating diseases at the interface between etiology and pathogenesis. Curr Opin Neurol. 2001; 14:253-258. [PubMed: 11371746]

Lee KH, Holdorf AD, Dustin ML, Chan AC, Allen PM, Shaw AS. T cell receptor signaling precedes immunological synapse formation. Science. 2002; 295:1539-1542. [PubMed: 11859198]

Liblau RS, Singer SM, McDevitt HO. Th1 and Th2 CD4+ T cells in the pathogenesis of organ-specific autoimmune diseases. Immunol Today. 1995; 16:34-38. [PubMed: 7880387]

Malek TR. The main function of IL-2 is to promote the development of T regulatory cells. J Leukoc Biol. 2003; 74:961-965. [PubMed: 12960253]

Manikwar P, Kiptoo P, Badawi AH, Buyuktimkin B, Siahaan TJ. Antigen-specific blocking of CD4specific immunological synapse formation using BPI and current therapies for autoimmune diseases. Med Res Rev. 2011

Metzler B, Wraith DC. Mucosal tolerance in a murine model of experimental autoimmune encephalomyelitis. Ann N Y Acad Sci. 1996; 778:228-242. [PubMed: 8610976]

Meyer O. Oral immunomodulation therapy in rheumatoid arthritis. Joint Bone Spine. 2000; 67:384392. [PubMed: 11143904]

Minagar A, Alexander JS. Blood-brain barrier disruption in multiple sclerosis. Mult Scler. 2003; 9:540-549. [PubMed: 14664465]

Murray JS, Oney S, Page JE, Kratochvil-Stava A, Hu Y, Makagiansar IT, Brown JC, Kobayashi N, Siahaan TJ. Suppression of type 1 diabetes in NOD mice by bifunctional peptide inhibitor: modulation of the immunological synapse formation. Chem Biol Drug Des. 2007; 70:227-236. [PubMed: 17718717]

O'Connor RA, Prendergast CT, Sabatos CA, Lau CW, Leech MD, Wraith DC, Anderton SM. Cutting edge: Th1 cells facilitate the entry of Th17 cells to the central nervous system during experimental autoimmune encephalomyelitis. J Immunol. 2008; 181:3750-3754. [PubMed: 18768826]

Prendergast CT, Anderton SM. Immune cell entry to central nervous system--current understanding and prospective therapeutic targets. Endocr Metab Immune Disord Drug Targets. 2009; 9:315327. [PubMed: 20028334] 
Reboldi A, Coisne C, Baumjohann D, Benvenuto F, Bottinelli D, Lira S, Uccelli A, Lanzavecchia A, Engelhardt B, Sallusto F. C-C chemokine receptor 6-regulated entry of TH-17 cells into the CNS through the choroid plexus is required for the initiation of EAE. Nat Immunol. 2009; 10:514-523. [PubMed: 19305396]

Ridwan R, Kiptoo P, Kobayashi N, Weir S, Hughes M, Williams T, Soegianto R, Siahaan TJ. Antigenspecific suppression of experimental autoimmune encephalomyelitis by a novel bifunctional peptide inhibitor: structure optimization and pharmacokinetics. J Pharmacol Exp Ther. 2010; 332:1136-1145. [PubMed: 20026673]

Santambrogio L, Sato AK, Fischer FR, Dorf ME, Stern LJ. Abundant empty class II MHC molecules on the surface of immature dendritic cells. Proc Natl Acad Sci U S A. 1999; 96:15050-15055. [PubMed: 10611336]

Sun D, Tani M, Newman TA, Krivacic K, Phillips M, Chernosky A, Gill P, Wei T, Griswold KJ, Ransohoff RM, Weller RO. Role of chemokines, neuronal projections, and the blood-brain barrier in the enhancement of cerebral EAE following focal brain damage. J Neuropathol Exp Neurol. 2000; 59:1031-1043. [PubMed: 11138923]

Tibbetts SA, Chirathaworn C, Nakashima M, Jois DS, Siahaan TJ, Chan MA, Benedict SH. Peptides derived from ICAM-1 and LFA-1 modulate T cell adhesion and immune function in a mixed lymphocyte culture. Transplantation. 1999; 68:685-692. [PubMed: 10507489]

Tibbetts SA, Seetharama Jois D, Siahaan TJ, Benedict SH, Chan MA. Linear and cyclic LFA-1 and ICAM-1 peptides inhibit T cell adhesion and function. Peptides. 2000; 21:1161-1167. [PubMed: 11035201]

Tonra JR, Reiseter BS, Kolbeck R, Nagashima K, Robertson R, Keyt B, Lindsay RM. Comparison of the timing of acute blood-brain barrier breakdown to rabbit immunoglobulin $\mathrm{G}$ in the cerebellum and spinal cord of mice with experimental autoimmune encephalomyelitis. J Comp Neurol. 2001; 430:131-144. [PubMed: 11135250]

Tseng SY, Dustin ML. T-cell activation: a multidimensional signaling network. Curr Opin Cell Biol. 2002; 14:575-580. [PubMed: 12231352]

Tuohy VK, Lu Z, Sobel RA, Laursen RA, Lees MB. Identification of an encephalitogenic determinant of myelin proteolipid protein for SJL mice. J Immunol. 1989; 142:1523-1527. [PubMed: 2465343]

Valitutti S, Dessing M, Aktories K, Gallati H, Lanzavecchia A. Sustained signaling leading to T cell activation results from prolonged $\mathrm{T}$ cell receptor occupancy. Role of $\mathrm{T}$ cell actin cytoskeleton. $\mathrm{J}$ Exp Med. 1995; 181:577-584. [PubMed: 7836913]

van der Merwe PA. Formation and function of the immunological synapse. Curr Opin Immunol. 2002; 14:293-298. [PubMed: 11973125]

Wraith DC. Therapeutic peptide vaccines for treatment of autoimmune diseases. Immunol Lett. 2009; 122:134-136. [PubMed: 19100774]

Youssef S, Stuve O, Patarroyo JC, Ruiz PJ, Radosevich JL, Hur EM, Bravo M, Mitchell DJ, Sobel RA, Steinman L, Zamvil SS. The HMG-CoA reductase inhibitor, atorvastatin, promotes a Th2 bias and reverses paralysis in central nervous system autoimmune disease. Nature. 2002; 420:78-84. [PubMed: 12422218]

Yusuf-Makagiansar H, Makagiansar IT, Siahaan TJ. Inhibition of the adherence of T-lymphocytes to epithelial cells by a cyclic peptide derived from inserted domain of lymphocyte functionassociated antigen-1. Inflammation. 2001; 25:203-214. [PubMed: 11403212]

Yusuf-Makagiansar H, Yakovleva TV, Tejo BA, Jones K, Hu Y, Verkhivker GM, Audus KL, Siahaan TJ. Sequence recognition of alpha-LFA-1-derived peptides by ICAM-1 cell receptors: inhibitors of T-cell adhesion. Chem Biol Drug Des. 2007; 70:237-246. [PubMed: 17718718]

Zepp J, Wu L, Li X. IL-17 receptor signaling and T helper 17-mediated autoimmune demyelinating disease. Trends Immunol. 2011; 32:232-239. [PubMed: 21493143]

Zhao H, Kiptoo P, Williams TD, Siahaan TJ, Topp EM. Immune response to controlled release of immunomodulating peptides in a murine experimental autoimmune encephalomyelitis (EAE) model. J Control Release. 2010; 141:145-152. [PubMed: 19748537] 

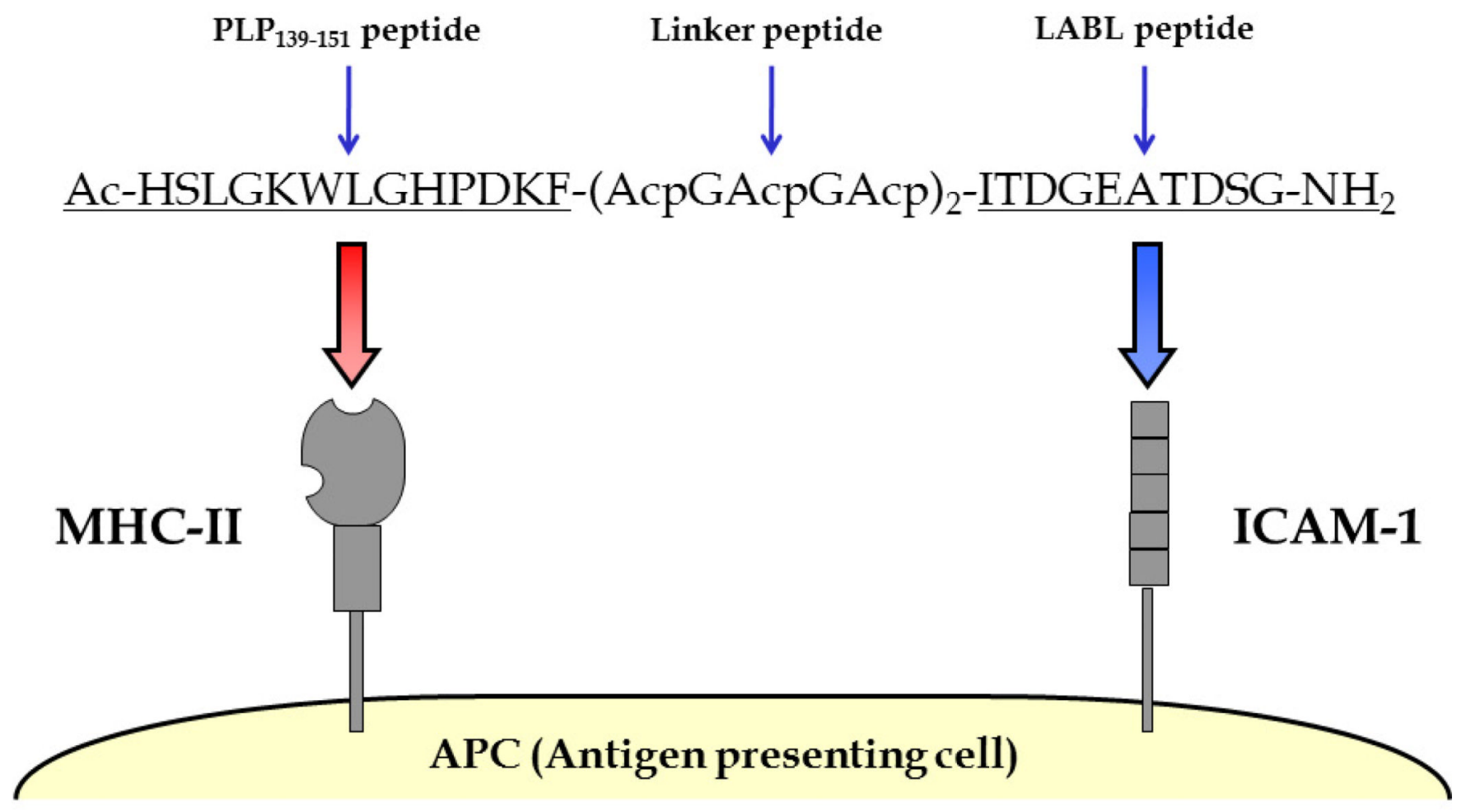

Figure 1.

Sequence and target receptors of PLP-BPI. PLP-BPI is a linear 33-amino acid peptide, which is composed of the antigenic peptide, PLP ${ }_{139-151}$ and the ICAM-1 binding peptide, LABL, which is derived from the $\alpha$-subunit of LFA-1 (CD11 $\mathrm{a}_{237-246}$ ). Both peptides are covalently conjugated to each other via a linker composed of $\varepsilon$-aminocaproic acid and glycine. The $\mathrm{N}$ - and $\mathrm{C}$ - termini of the peptide are capped by acetylation and amidation, respectively. The hypothesis is that the $\mathrm{PLP}_{139-151}$ portion will bind to $\mathrm{MHC}-\mathrm{II}\left(\mathrm{I}-\mathrm{A}^{\mathrm{s}}\right)$ and LABL will simultaneously bind to ICAM-1 on the surface of the APC. 


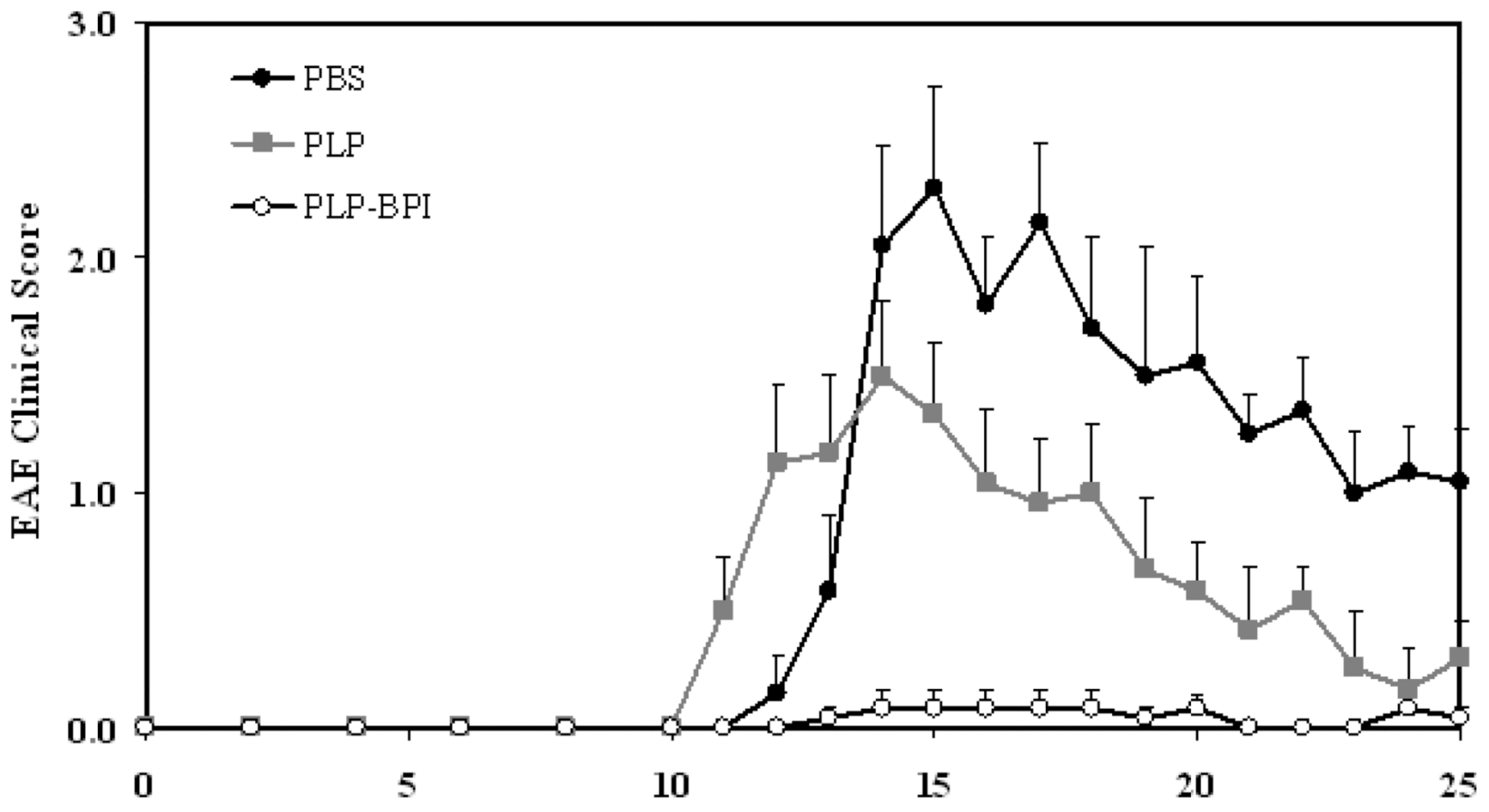

Day

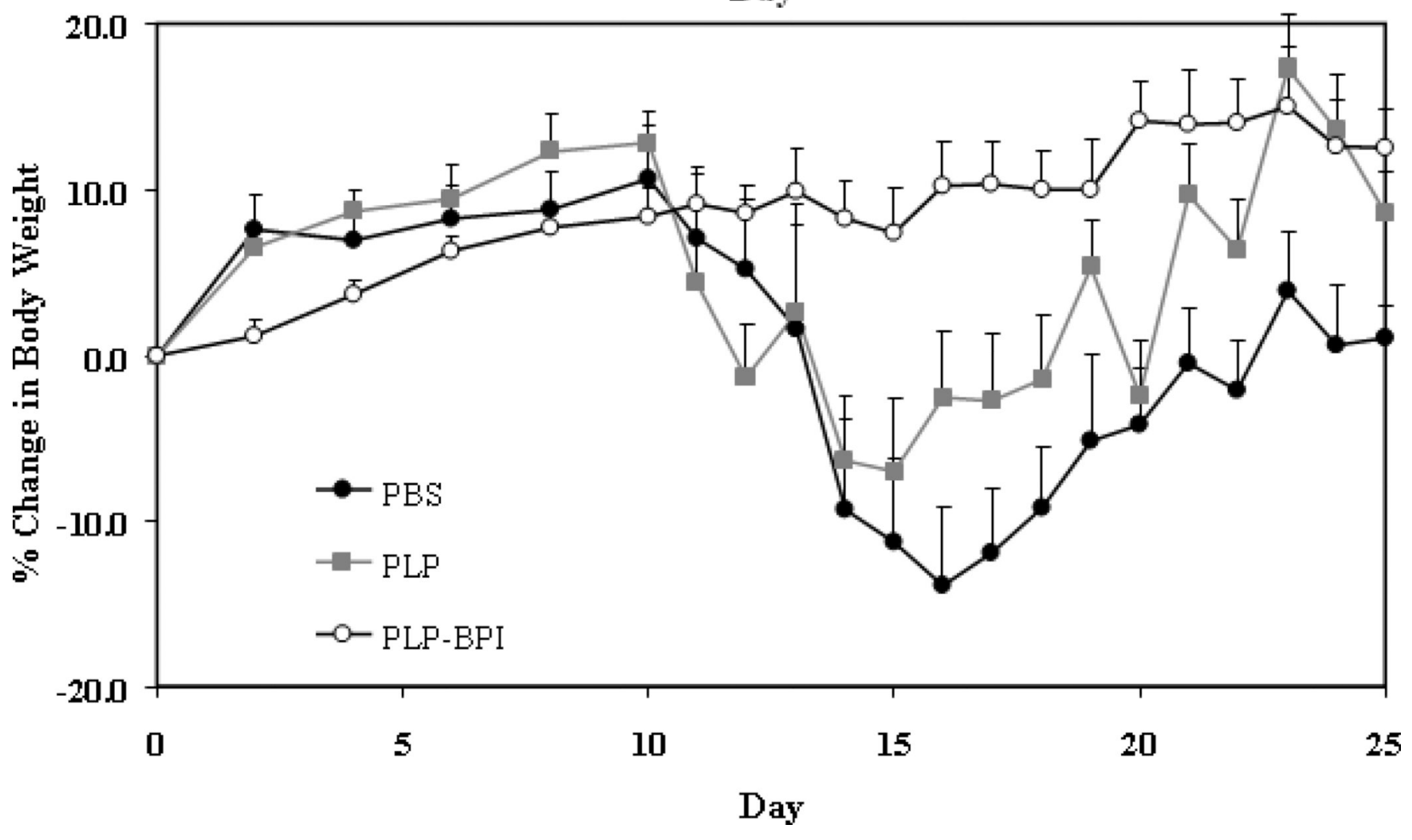

Figure 2. 
In vivo efficacies of PLP-BPI and PLP in suppressing EAE in the mouse model upon vaccination with peptides and immunization with PLP/CFA on day 0. PBS-treated mice received subcutaneous injections of $100 \mu 1$ PBS on days $-11,-8$, and -5 . PLP-BPI- and PLP-treated mice received $100 \mathrm{nmol} / 100 \mu \mathrm{l}$ PBS on days $-11,-8$, and -5 . The efficacy of the peptide was determined by (A) clinical disease score of EAE and (B) percent change in body weight. Results are expressed as the mean \pm SEM $(n=12)$. EAE scores from all PLPBPI treated mice were significantly lower than those of PBS- and PLP-treated mice ( $p<$ 0.0001). Loss of body weight was also significantly lower in PLP-BPI-treated mice compared to those treated with PBS $(p<0.0001)$ and PLP $(p<0.001)$. For statistical analysis, data points from days 10 to 25 were used. 
IL-6

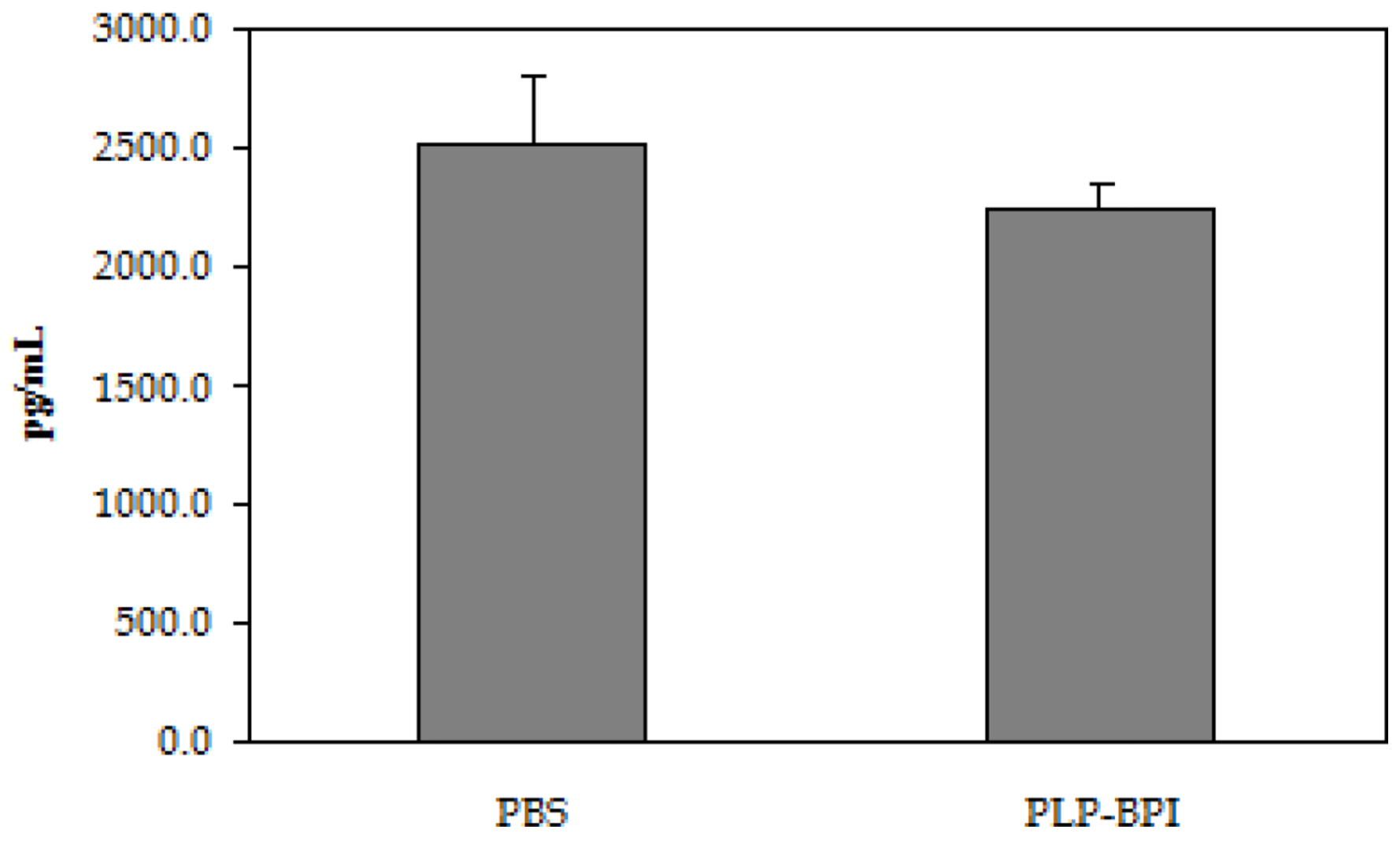




\section{IL-17}

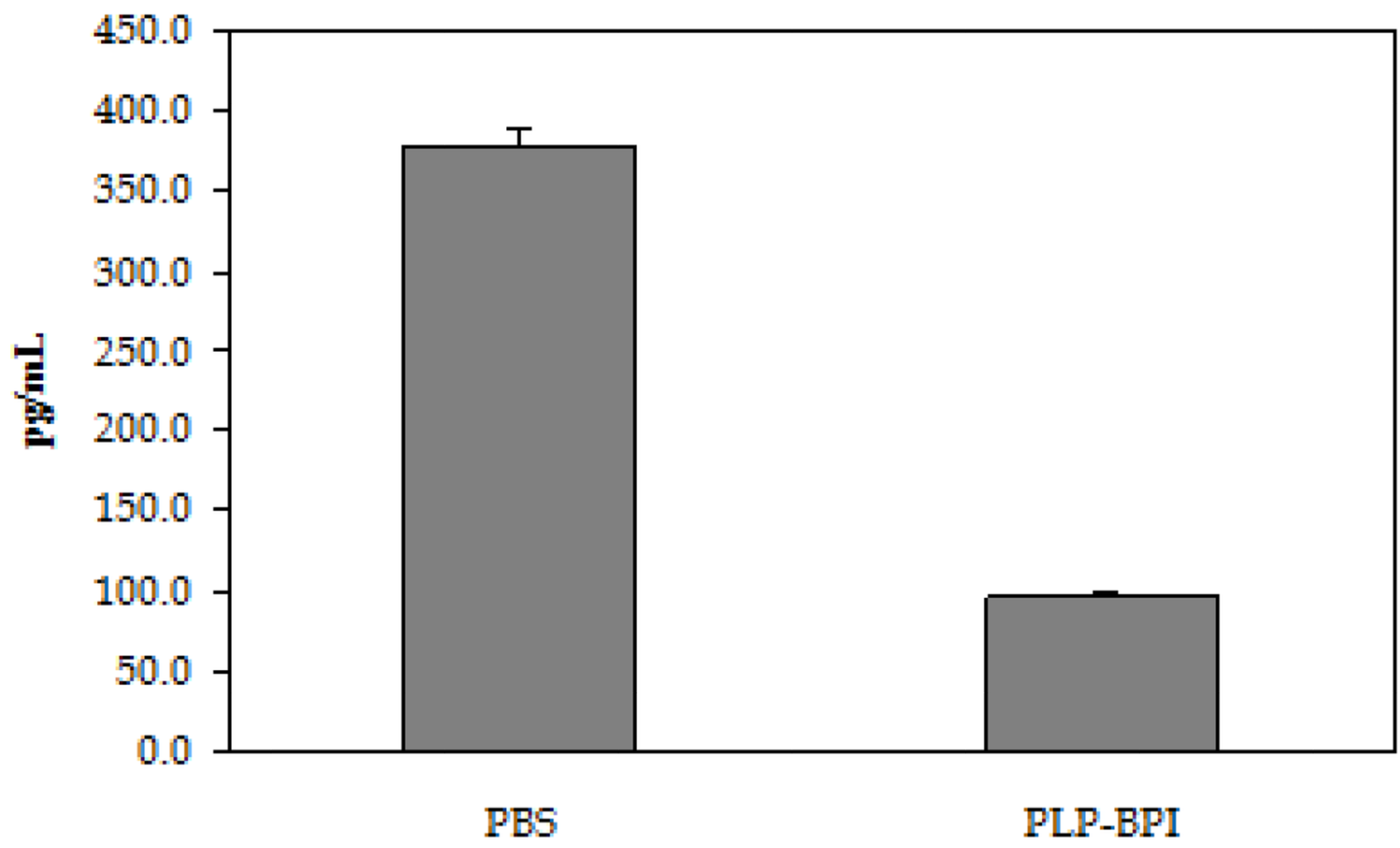




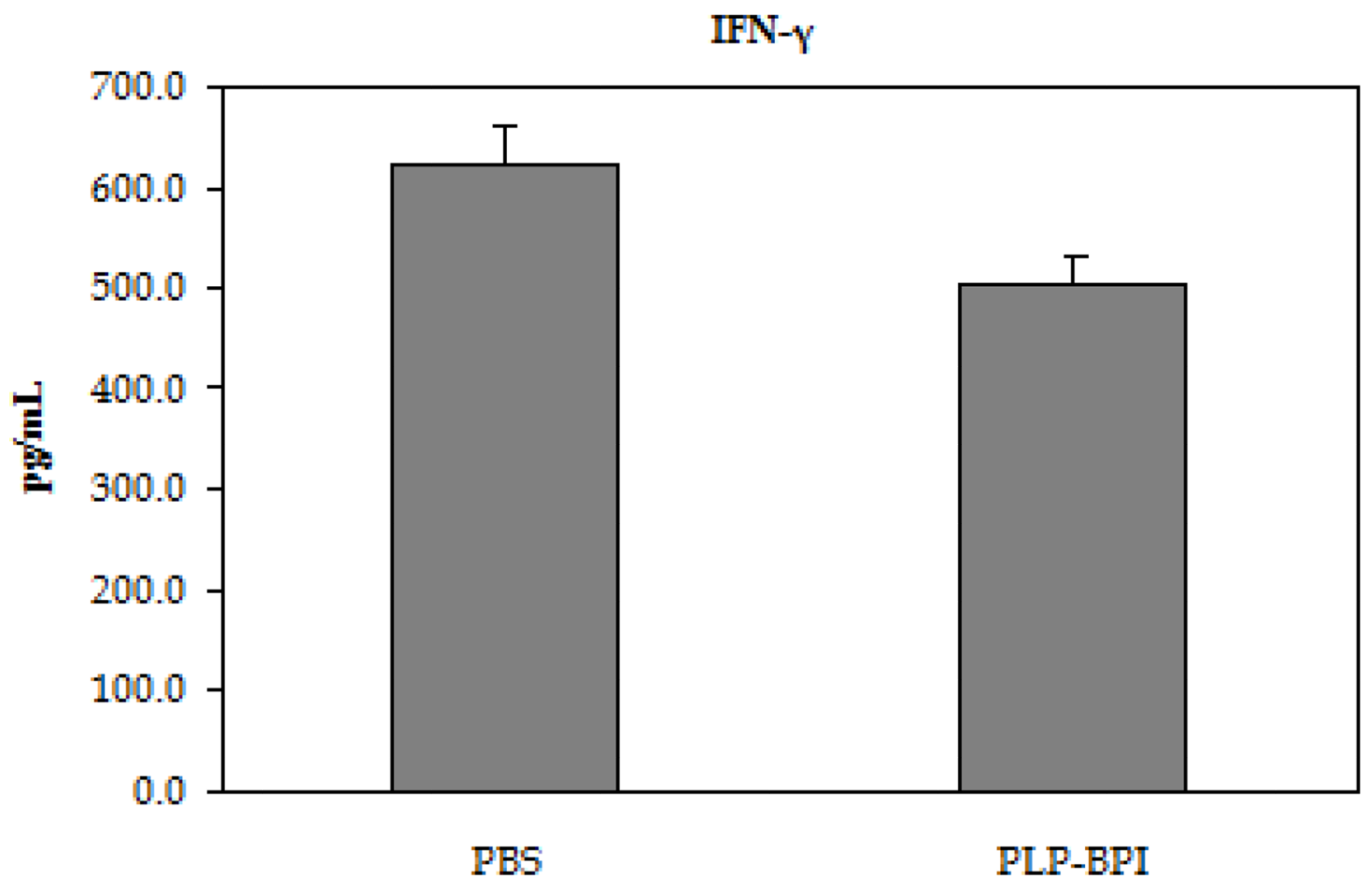

Figure 3.

Concentrations of the pro-inflammatory cytokines from the cell culture supernatant (IL-6, IFN- $\gamma$ and IL-17). Splenocytes were isolated from the spleens of EAE-induced mice that were treated with either PBS or PLP-BPI on days $-11,-8$, and -5 . The pooled splenocytes $(\mathrm{n}=3$ mice $)$ were stimulated in vitro with $\mathrm{PLP}_{139-151}$ and supernatant was isolated 72 hours later for cytokine detection. Statistical significance values for the concentration of cytokines in PLP-BPI treated mice compared to that in the PBS group are as follows: $\mathbf{A}, p>0.05, \mathbf{B}, p$ $<0.0001, \mathbf{C}, p<0.05$. 

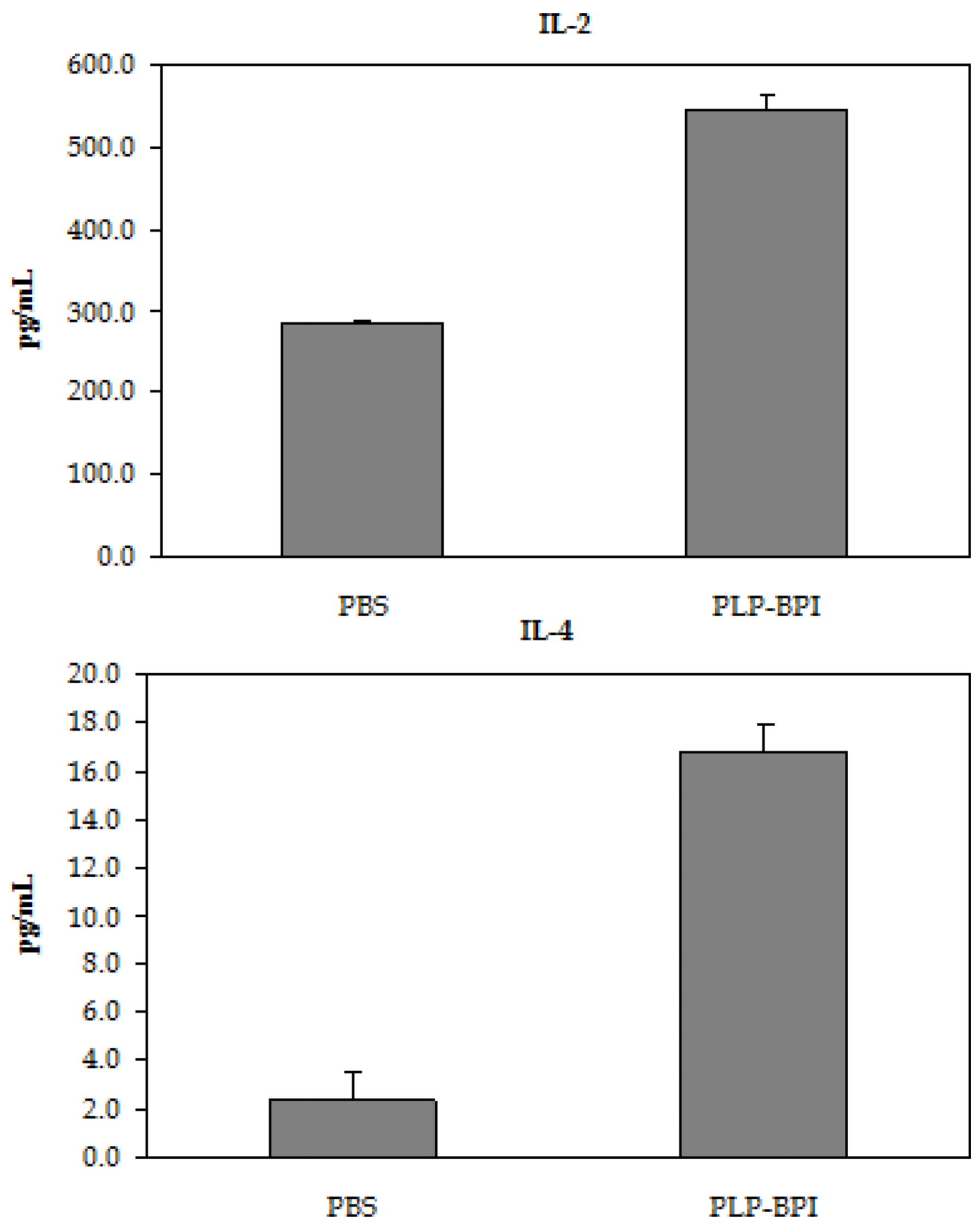

Neuropharmacology. Author manuscript; available in PMC 2013 March 1. 


\section{IL-5}

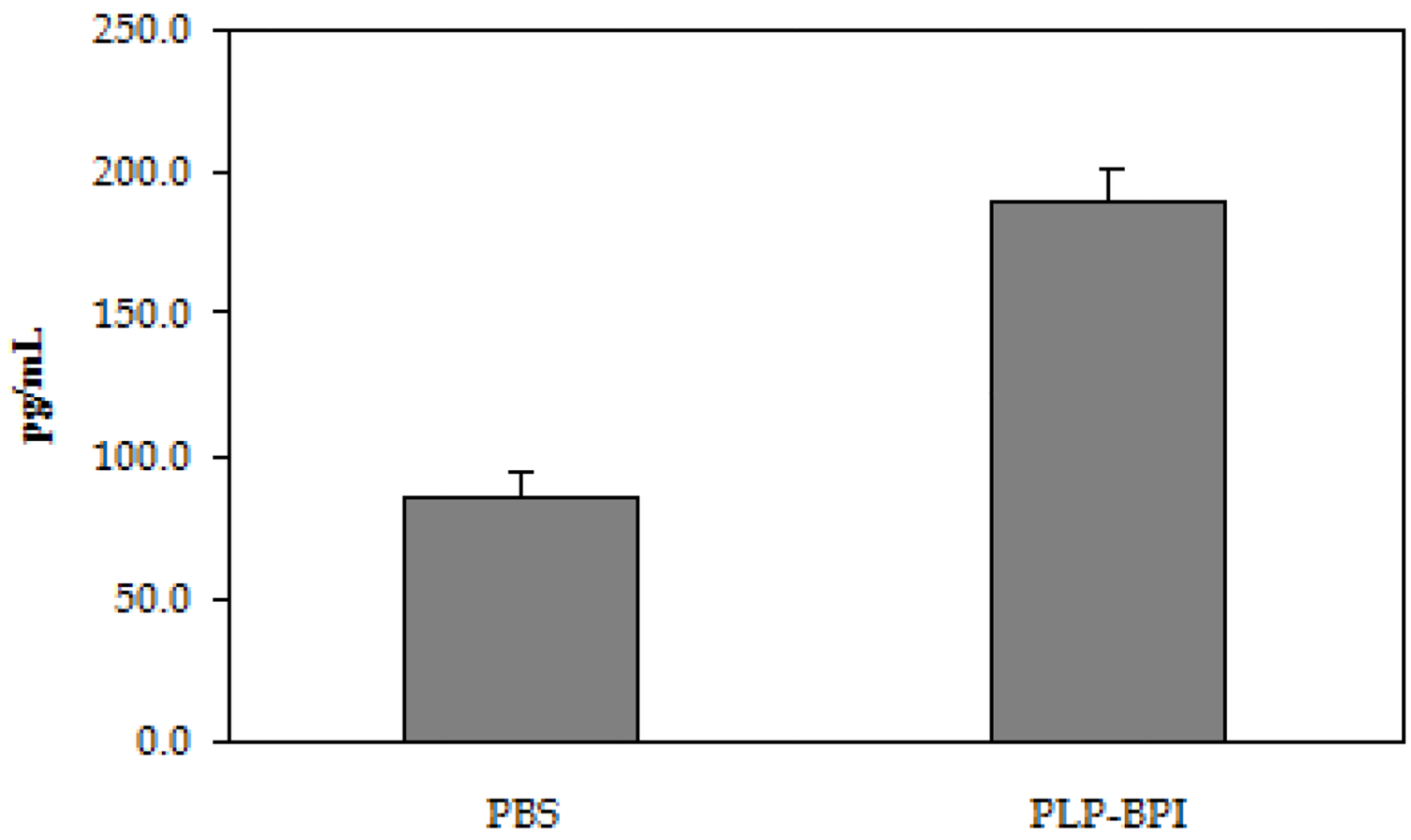

Figure 4.

Concentrations of the regulatory (IL-2) and suppressor (IL-4 and IL-5) cytokines from the cell culture supernatant. Splenocytes were isolated from the spleens of EA- induced mice that were treated with either PBS or PLP-BPI on days $-11,-8$, and -5 . The pooled splenocytes $\left(\mathrm{n}=3\right.$ mice) were stimulated in vitro with PLP $_{139-151}$ and supernatant was isolated 72 hours later for cytokine detection. Statistical significance values for the concentration of cytokines in PLP-BPI treated mice compared to that in the PBS group are as follows: $\mathbf{A}, p<0.0001, \mathbf{B}, p<0.0001, \mathbf{C}, p<0.001$. 
No EAE

Figure 5.
EAE - PBS treated
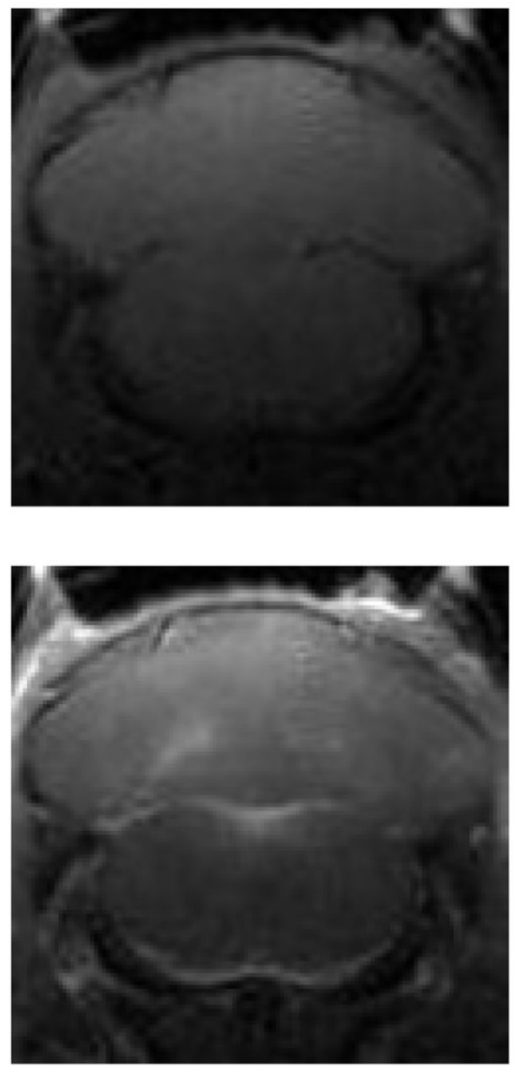

\section{EAE - PLP-BPI treated}
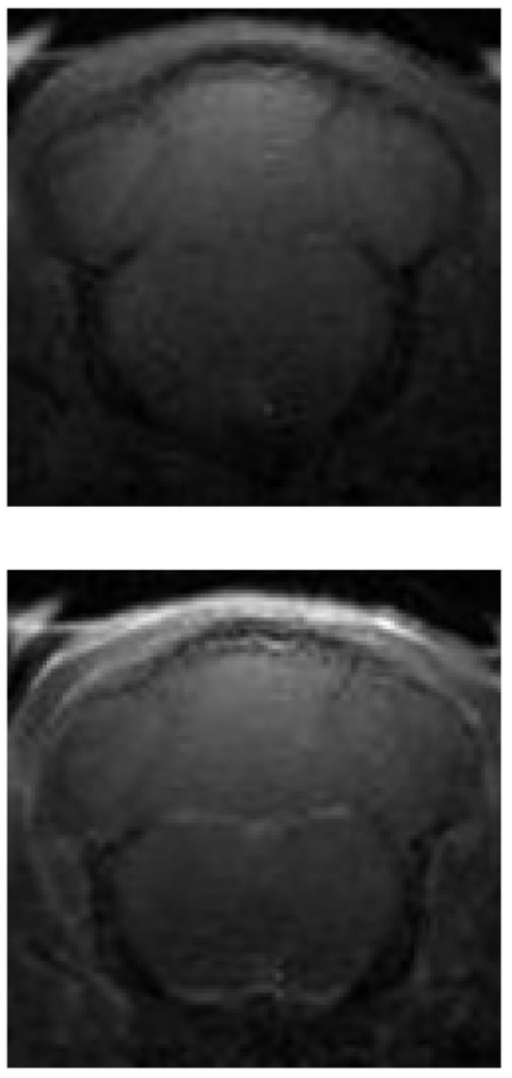

Representative scans of the cerebellum and brainstem of three different groups of mice $(\mathrm{n}=$ 5/group). The first group consisted of normal SJL mice with no EAE induced. The second and third groups were mice treated with either PBS or PLP-BPI on days $-11,-8$, and -5 and immunized to develop EAE on day 0 . Each mouse was scanned before $\left(\mathrm{v}_{0}\right)$ and after $\left(\mathrm{v}_{1}\right)$ an i.p. bolus injection of Gd-DTPA contrast agent. There is obvious enhancement in signal within the ROI of mice treated with PBS, but no obvious enhancement in signal in normal mice and PLP-BP- treated mice. 


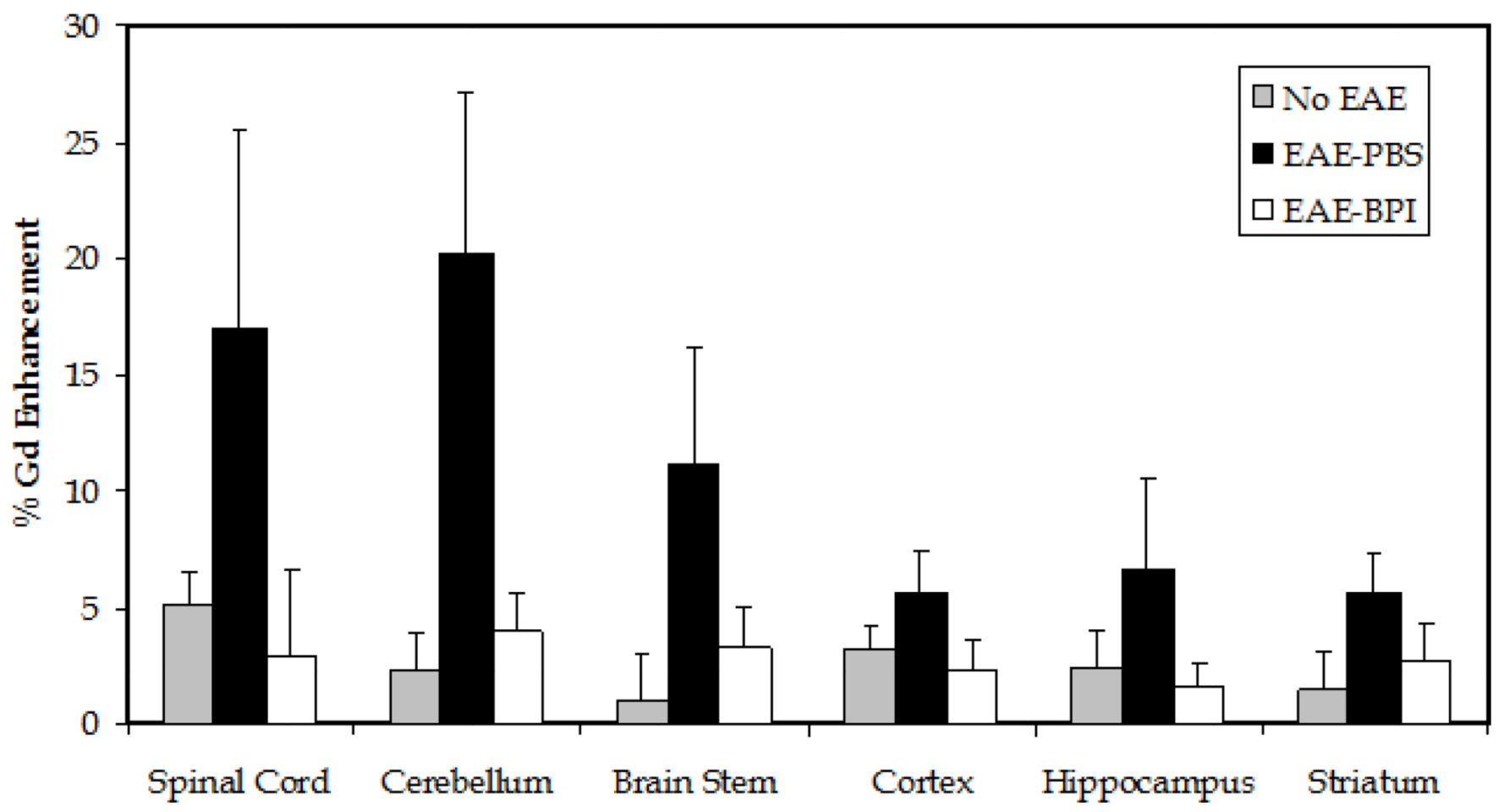

Figure 6.

Quantitative signal enhancement using Gd-DTPA. Each mouse ( $n=5$ per group) was scanned before $\left(\mathrm{v}_{0}\right)$ and after $\left(\mathrm{v}_{1}\right)$ an i.p. bolus injection of the Gd-DTPA contrast agent. The percentage was calculated from the ratio of signal enhancement using the equation $\left[\mathrm{v}_{1}-\mathrm{v}_{0}\right] /$ $\mathrm{v}_{0}$. The signal enhancement within the ROI can be correlated to the breakdown of the BBB. All the regions of the brain had greater enhancement of the signal within the ROI in the PBS-treated mice than in the normal mice (no EAE induced) and PLP-BPI treated mice. The cerebellum was the only region in which there was a statistically significant difference between groups. Normal control and PLP-BPI-treated mice had a significantly lower signal enhancement within the ROI of the cerebellum $(p<0.05)$. 
Table 1

Summary of in vivo results.

\begin{tabular}{clcc}
\hline Group & Dose $^{\boldsymbol{a}}$ & Incidence of disease $^{\boldsymbol{b}}$ & $\begin{array}{c}\text { Mean maximal score } \\
\mathbf{\pm} \mathbf{S E M}^{\boldsymbol{c}}\end{array}$ \\
\hline PBS & $100 \mu \mathrm{l} /$ mouse on days $-11,-8$, and -5 & $12 / 12$ & $2.30 \pm 0.43$ \\
PLP & $100 \mathrm{nmol} /$ mouse on days $-11,-8$, and -5 & $12 / 12$ & $1.50 \pm 0.31$ \\
PLP-BPI & $100 \mathrm{nmol} /$ mouse on days $-11,-8$, and -5 & $1 / 12$ & $0.08 \pm 0.08$ \\
\hline
\end{tabular}

${ }^{a}$ All injections were administered subcateneously.

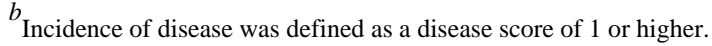

${ }^{c}$ Mean maximal disease scores were expressed as mean $\pm \operatorname{SEM}(\mathrm{n}=12)$. 